\title{
OXIDATIVE CONVERSION OF ISOPROPYL ALCOHOL TO ACETONE OVER MODIFIED ZEOLITE CATALYSTS
}

\author{
Agadadash ALIYEV, Agil SAFAROV* and Zumrud SHABANOVA \\ Institute of Catalysis and Inorganic Chemistry named after academician M.F.Nagiyev, Baku, Azerbaijan, AZ1143, H.Javid Ave. 113
}

The catalytic activity of zeolites; A-type, natural clinoptilolite and mordenite modified with $\mathrm{Cu}^{2+}$ and $\mathrm{Pd}^{2+}$ cations via ion exchange was studied in the oxidative conversion of isopropyl alcohol to acetone under the action of oxygen. It is established that the highest activity and selectivity in this reaction is exhibited by natural mordenite containing $0.5 \%$ (wt.) $\mathrm{Cu}^{2+}$ and $0.1 \%$ (wt.) $\mathrm{Pd}^{2+}$. The kinetics of this catalytic reaction is studied in the range of: temperature $150-250^{\circ} \mathrm{C}$, space velocity 1000 $2500 \mathrm{~h}^{-1}$ and different molar ratios of the reactants and inert diluent. Based on the experimental data, a possible stepwise mechanism is proposed and theoretically grounded kinetic model of the process is developed.

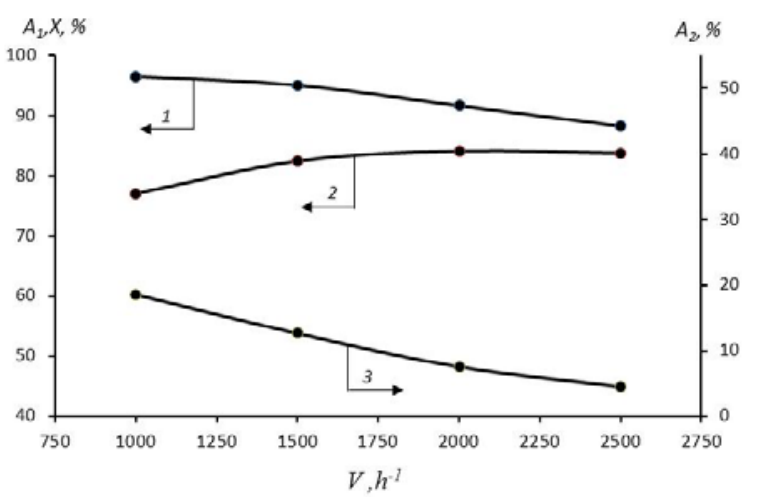

\section{INTRODUCTION}

Acetone is one of the important products of basic organic synthesis. The major industrial methods for producing acetone is the oxidative dehydrogenation of isopropyl alcohol in the vapor phase which proceeds in the presence of catalysts such as copper, silver, nickel, platinum and the others. ${ }^{1,2}$ These processes proceed relatively at high temperatures. Therefore they are energy-consuming.

Some literature has reported the process of oxidation of isopropyl alcohol to acetone in the presence of metal-zeolite catalysts. ${ }^{1-4}$ It has been shown that the oxidation of isopropyl alcohol over the modified zeolite $\mathrm{NaY}$ though has a high selectivity on acetone (97.0\%) but the yield of acetone is only $6.0 \%{ }^{3}$ The authors ${ }^{4}$ were achieved the yield of acetone $-33 \%$ in reaction of oxidative conversion of isopropyl alcohol over natural zeolite - clinoptilolite containing 4\% (wt.) of silver. However, the reaction was complicated by the formation of propylene.

A study of kinetics and mechanism of the reaction of oxidation of isopropyl alcohol to acetone over the modified zeolites with different cations catalysts is not described in the literature. In the present paper, it has been given the results of the investigation on selection of the high efficiency modified zeolite catalyst for reaction of oxidative conversion of isopropyl alcohol to acetone, also the results of a study of the kinetics and mechanism of this reaction.

\section{EXPERIMENTAL}

It has been prepared a series of specimens of metal-zeolite catalysts modified with copper and palladium cations on the basis of synthetic zeolite type A and natural zeolites -

\footnotetext{
*Corresponding author: agil_s@mail.ru
} 
clinoptilolite and mordenite. Catalysts were synthesized by ion exchange method. ${ }^{5}$ Testing activity of the synthesized samples of metal zeolites catalysts carried out in a U-shaped flow reactor directly connected to the analytical unit. The analyses of the products of the process was performed by gas chromatography Agilent 7820A using a column, DB-624, helium as the carrier gas, hot wire detector and program control of the temperature.

The reactor was loaded with $2 \mathrm{~cm}^{3}$ of catalyst with a particle size $0.23-0.63 \mathrm{~mm}$, and then was activated for 2 hours in air stream at temperature, $350^{\circ} \mathrm{C}$ and space velocity, $3000 \mathrm{~h}^{-1}$. The reactor was placed in an air electric oven with automatic temperature control.

Feed of raw material was carried out with a pump. Mixture of vapors of isopropyl alcohol with oxygen and helium was fed one of the knees of the reactor with the catalyst bed. The temperature in the middle of the catalyst layer was measured with a thermocouple and recorded by a potentiometer.

Composition of the reaction mixture was determined at various intervals by gas chromatography, taking samples from the reaction zone directly through six-way crane mounted on the output of the reactor. In experiments has been used isopropyl alcohol with purity of $98.6 \%$.

The kinetic of the reaction has been investigated at atmospheric pressure in the range of temperature $150-250^{\circ} \mathrm{C}$, space velocity, $1000-2500 \mathrm{~h}^{-1}$ and at different partial pressures of the reactants: $\mathrm{P}_{\mathrm{i}-\mathrm{C}_{3} \mathrm{H}_{7} \mathrm{OH}}=0.1 \div 0.5 \mathrm{~atm}, \mathrm{P}_{\mathrm{O}_{2}}=0.1 \div 0.5 \mathrm{~atm}$. Runs performed at several feed rates and using granules of the catalyst with different sizes showed that external and internal mass transfer effects were negligible under the studied experimental conditions, so the processes were carried out under conditions allowing the reaction proceeds in the kinetic region.

\section{RESULTS AND DISCUSSION}

The results of the testing of the activity of the samples of the synthesized metal-zeolite catalysts in the reaction of partial oxidation of isopropyl alcohol to acetone in the presence of molecular oxygen are presented in Table 1. Over these catalysts the reaction is accompanied by deep oxidation and dehydration of isopropyl alcohol with forming carbon dioxide and propylene respectively. It follows from the data of Table 1 that the type of zeolite, distribution of acid sites on the catalyst surface, concentrations and nature of cations, temperature, contact time and molar ratio of reactants influence on the yields of individual products significantly.

Table 1 shows that catalysts prepared on the basis of natural mordenite are much more active in the partial oxidation reaction of isopropyl alcohol to acetone. At temperature $-230^{\circ} \mathrm{C}$, mole ratios of alcohol:oxygen:helium $-1: 2: 1.8$ and space velocity of $2400 \mathrm{~h}^{-1}$ over zeolite catalyst - natural mordenite modified with copper and palladium cations the yield of acetone reaches $85.4 \%$ at selectivity of $94.2 \%$. Under the same conditions on the catalysts $\mathrm{CuPdCaA}, \mathrm{CuPdNaA}$ the yield of acetone does not exceed $65.8 \%$. Differences in the activity and selectivity of catalysts are related with change of distribution of acid sites on the surface zeolite. It should be noted that the yield of individual products is greatly affected by the distribution of acid sites (the distribution of acid sites on the surface changes when metal cations are introduced into the zeolites) and by the concentration and nature of a cation.

Analysis of the data given in Table 1, shows that the metal zeolite catalyst synthesized from natural mordenite by an ion exchange method and containing $0.5 \%$ (wt.) $\mathrm{Cu}^{2+}$ and $0.1 \%$ (wt.) $\mathrm{Pd}^{2+}$ shows the highest activity in this reaction. Kinetic regularities of this reaction have been studied over the metal-zeolite catalyst mordenite $\mathrm{CuPd}$ of this composition in the absence of diffusion inhibition. Characteristic curves of study the kinetics of the process are presented in Figures 1-4.

Figure 1 shows curves of dependence of the yields and conversion from temperature. As seen from the figure, in the all of studied range of temperature $\left(150-250^{\circ} \mathrm{C}\right)$ with increasing temperature the conversion and the yield of carbon dioxide are increasing, and dependence of the yield curve of acetone passes through a maximum. Decreasing of the yield of acetone at temperatures above $230^{\circ} \mathrm{C}$ is a result of the higher rate of deep oxidation of isopropyl alcohol into carbon dioxide.

Table 1

The results of the investigation of vapor-phase catalytic oxidation of isopropyl alcohol to acetone at space velocity $\mathrm{V}=2400 \mathrm{~h}^{-1}$ and molar ratio of the reactants alcohol:oxygen:helium $=1: 2: 1.8$

\begin{tabular}{|c|c|c|c|c|c|c|c|c|}
\hline \multirow{2}{*}{ № } & \multirow{2}{*}{ Zeolite } & \multirow{2}{*}{$\mathrm{T}^{0} \mathrm{C}$} & \multicolumn{2}{|c|}{ Composition } & \multirow{2}{*}{$\begin{array}{c}\text { Conversion of } \\
\text { alcohol, } \%\end{array}$} & \multicolumn{3}{|c|}{ Yields, \% } \\
\hline & & & $\mathrm{Cu}^{2+}$ & $\mathrm{Pd}^{2+}$ & & Acetone & $\mathrm{CO}_{2}$ & Propylene \\
\hline 1 & $\mathrm{CaA}$ & 150 & - & - & 13.6 & 6.6 & 2.7 & 4.3 \\
\hline 2 & - & 230 & - & - & 30.2 & 9.0 & 10.2 & 11.0 \\
\hline 3 & & 150 & - & 0.1 & 40.4 & 24.4 & 11.8 & 8.2 \\
\hline 4 & - & 230 & - & 0.1 & 74.6 & 25.9 & 31.2 & 17.5 \\
\hline 5 & - & 230 & 0.5 & - & 69.7 & 33.6 & 27.0 & 9.1 \\
\hline 6 & - & 230 & 0.5 & 0.1 & 69.6 & 53.1 & 6.0 & 10.5 \\
\hline
\end{tabular}


Table 1 (continued)

\begin{tabular}{l|c|c|c|c|c|c|c|cc}
\hline 7 & - & 230 & 3 & 1 & 82.5 & 65.8 & 6.8 & 9.9 \\
8 & $\mathrm{NaA}$ & 200 & 3 & 1 & 62.6 & 38.8 & 0.9 & 22.9 \\
9 & - & 230 & 3 & 1 & 82.7 & 44.9 & 1.7 & 36.1 \\
& - & 200 & 5 & 1 & 68.7 & 51.3 & 1.7 & 15.7 \\
10 & - & 230 & 5 & 1 & 85.8 & 54.5 & 2.5 & 28.8 \\
11 & Clinoptilolite & 150 & 0.5 & 0.1 & 66.7 & 63.6 & 3.1 & - & - \\
12 & - & 200 & 0.5 & 0.1 & 96.7 & 84.7 & 12 & - \\
13 & - & 230 & 0.5 & 0.1 & 99.5 & 62.2 & 37.3 & - \\
14 & Mordenite & 150 & 0.5 & 0.1 & 48.7 & 48.4 & 0.3 & - \\
15 & - & 200 & 0.5 & 0.1 & 79.6 & 76.2 & 3.4 & - \\
16 & - & 230 & 0.5 & 0.1 & 90.7 & 85.4 & 5.3 & - \\
17 & - & 250 & 0.5 & 0.1 & 93 & 84.9 & 8.1 & - \\
\hline
\end{tabular}

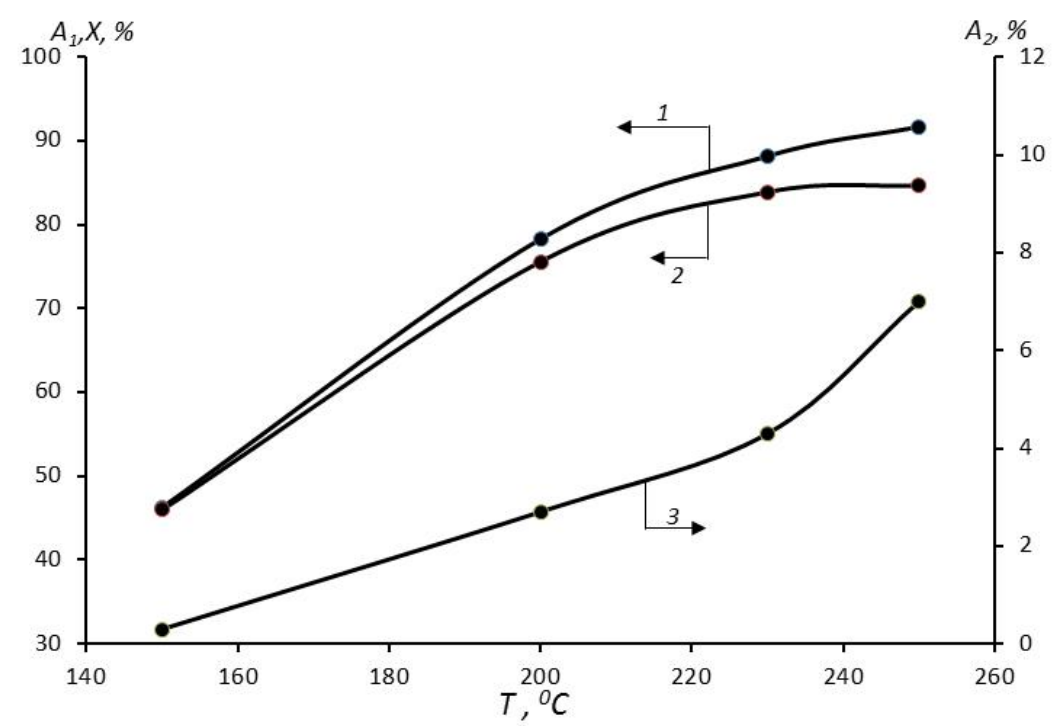

Fig. 1 - Dependence of conversion of isopropyl alcohol (1), yields of acetone (2) and carbon dioxide (3) from the temperature at a molar ratio of alcohol:oxygen:helium $=1: 2: 2$, space velocity $\mathrm{V}=2500 \mathrm{~h}^{-1}$ for natural mordenite, containing $0.5 \%$ (wt.) $\mathrm{Cu}^{2+}$ and $0.1 \%$ (wt.) $\mathrm{Pd}^{2+}$.

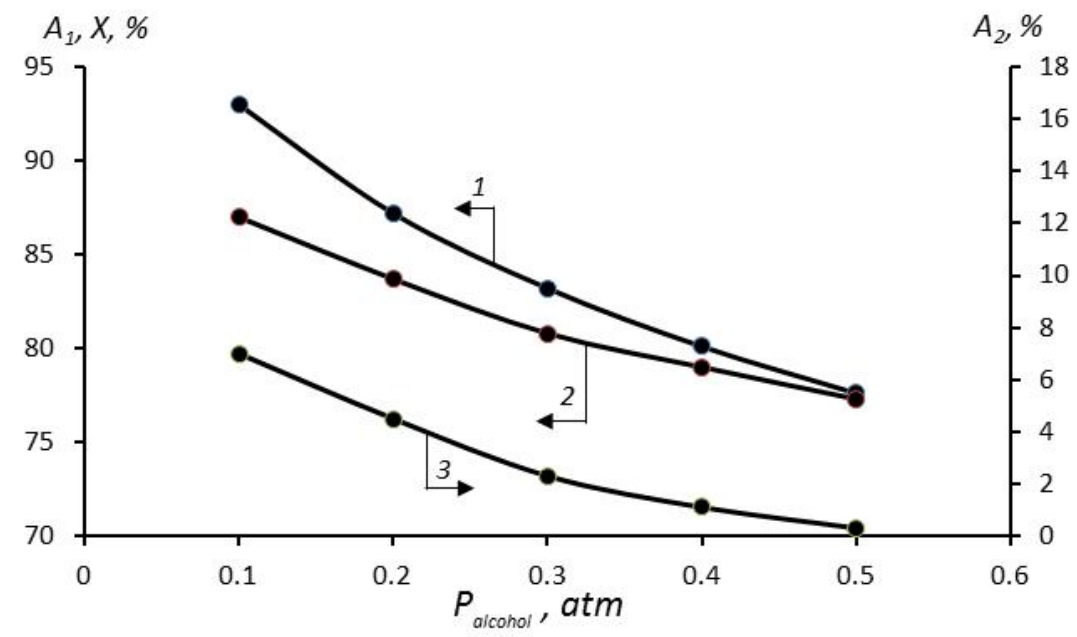

Fig. 2 - Influence of partial pressure of isopropyl alcohol on the proceeding of reaction at temperature of $230^{\circ} \mathrm{C}$, partial pressure of oxygen at $0.4 \mathrm{~atm}$ and space velocity of $\mathrm{V}-2500 \mathrm{~h}^{-1}$ over natural mordenite containing $0.5 \%$ (wt.) $\mathrm{Cu}^{2+}$ and $0.1 \%\left(\mathrm{wt}\right.$.) $\mathrm{Pd}^{2+}$ ( 1 - conversion, 2 - yield of acetone, 3 - yield of carbon dioxide). 


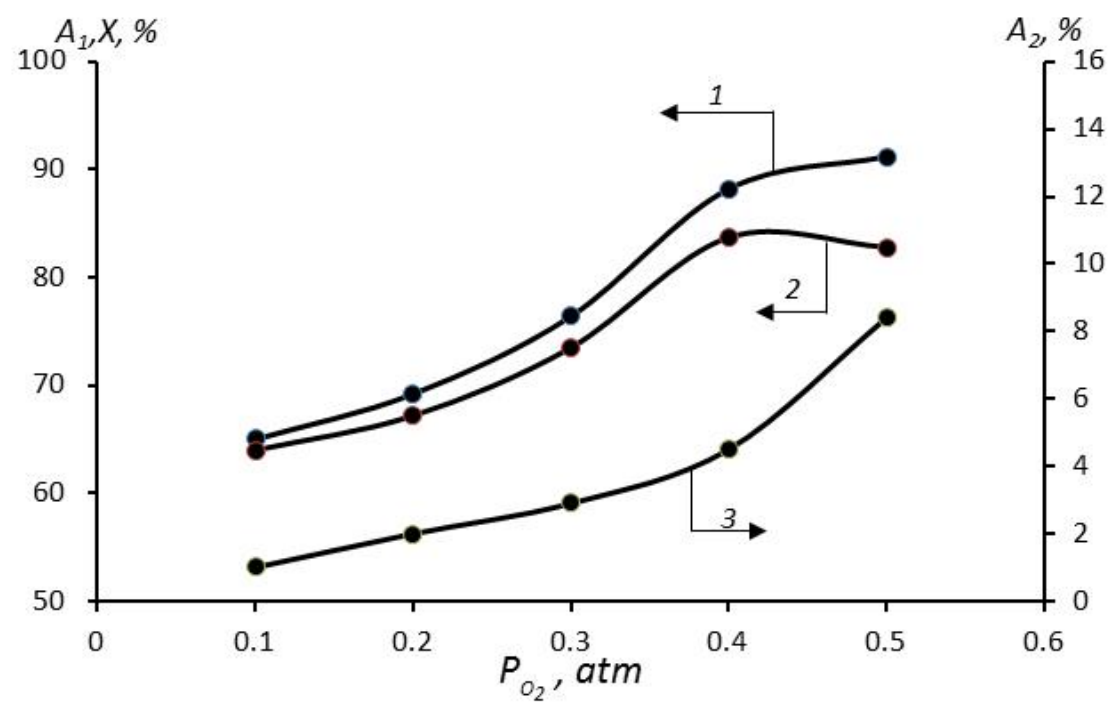

Fig. 3 - Influence of partial pressure of oxygen on the proceeding of reaction at temperature of $230^{\circ} \mathrm{C}$, partial pressure of isopropyl alcohol at $0.4 \mathrm{~atm}$ and space velocity of $\mathrm{V}-2500 \mathrm{~h}^{-1}$ over natural mordenite containing $0.5 \%$ (wt.) $\mathrm{Cu}^{2+}$ and $0.1 \%$ (wt.) $\mathrm{Pd}^{2+}(1$ - conversion, 2 - yield of acetone, 3 - yield of carbon dioxide).

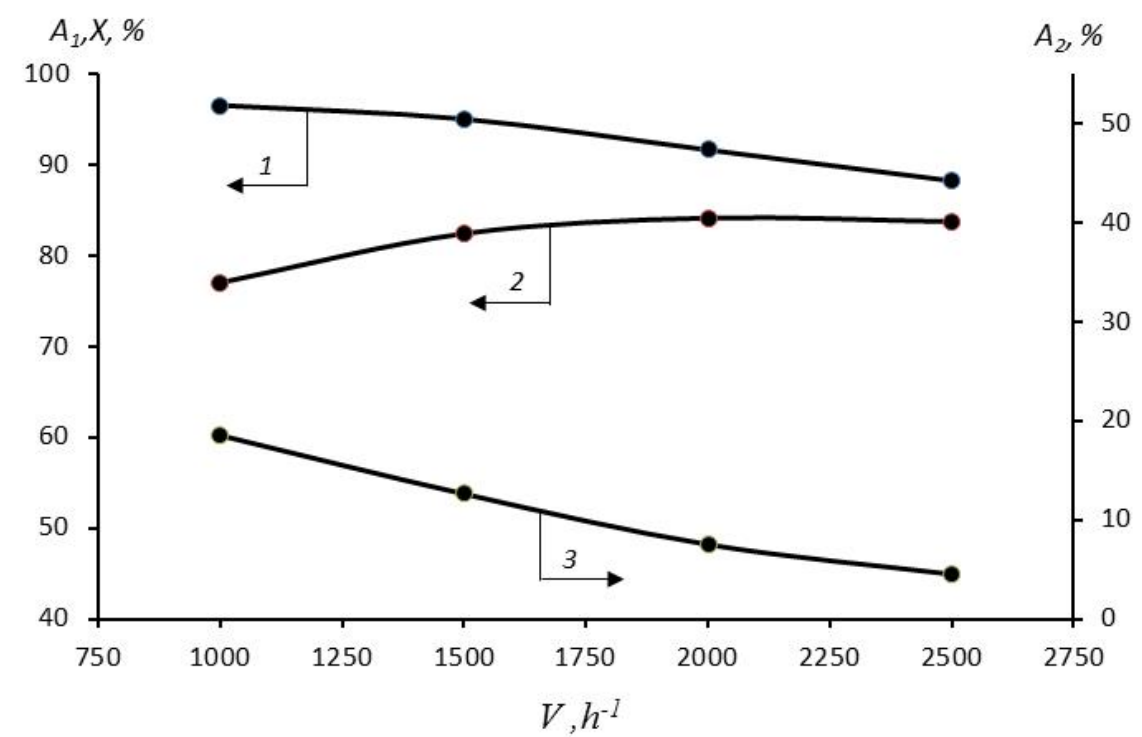

Fig. 4 - Influence of space velocity on the proceeding of the reaction at temperature of $230^{\circ} \mathrm{C}$ and molar ratio of the reactants alcohol:oxygen:helium=1:2:2 over natural mordenite containing $0.5 \%$ (wt.) $\mathrm{Cu}^{2+}$ and $0.1 \%$ (wt.) $\mathrm{Pd}^{2+}(1-$ conversion, $2-$ yield of acetone, 3 - yield of carbon dioxide).

The results of the investigations of influence of partial pressures of the reagents on proceeding of reaction are shown in Figure 2 and Figure 3.

As can be seen from Figure 2 at temperature of $230^{\circ} \mathrm{C}$, space velocity of $2500 \mathrm{~h}^{-1}$ and $\mathrm{P}_{\mathrm{O}_{2}}-0.4 \mathrm{~atm}$ with increasing of partial pressure of isopropyl alcohol, $\mathrm{P}_{\mathrm{i}-\mathrm{C}_{3} \mathrm{H}_{7} \mathrm{OH}}$ from 0.1 to $0.5 \mathrm{~atm}$ the yield of acetone decreases. This is due to the blocking of oxygen coordination to the active centers of the catalyst by molecules of isopropyl alcohol.
The study results of influence of partial pressure of oxygen in the range of 0.1-0.5 atm to the yield of reaction products at a partial pressure of isopropyl alcohol $\mathrm{P}_{\mathrm{i}-\mathrm{C}_{3} \mathrm{H}_{7} \mathrm{OH}}=0.2$ atm $\left(230^{\circ} \mathrm{C}, \mathrm{V}=\right.$ $2500 \mathrm{~h}^{-1}$ ) are shown in Fig. 3. As can be seen from the figure, increasing partial pressure of oxygen from 0.1 to 0.4 leads to increase of the yield of acetone from $64 \%$ to $83.9 \%$, and further increasing leads to decreasing of the yield of acetone. This can be explained by an increasing of the rate of deep oxidation. 
Influence of space velocity on reaction course presented in Figure 4, which shows that with increasing space velocity from $1000 \mathrm{~h}^{-1}$ to $2400 \mathrm{~h}^{-1}$ the yields of acetone and carbon dioxide are decreasing, which can be explained by decreasing of contact time.
On the basis of the kinetic experimental data it has been suggested the following kinetic scheme of the reaction of gas-phase oxidation of isopropyl alcohol to acetone:

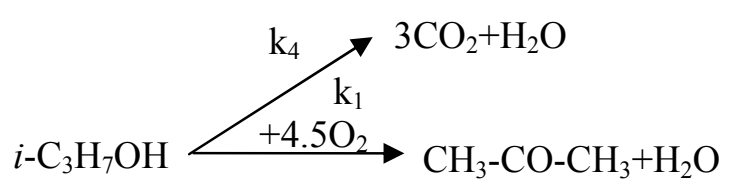

$+1 / 2 \mathrm{O}_{2}$

Based on the analysis of literature materials ${ }^{6-9}$ we suggested the following stepwise mechanism for formation of acetone (AS): during the adsorption of isopropyl alcohol (AL) there is its protonation with participation of Bronsted acid sites of the catalyst with subsequent elimination of water and formation of surface alkoxide. Conversion of surface alkoxide to acetone proceeds in result its interaction with the surface nucleophilic oxygen through formation such a ketone surface compound. Then it has been decomposition such a ketone surface compound to acetone and recovers the initial state of the catalyst. A simplified scheme of the stepwise mechanism looks as follows:

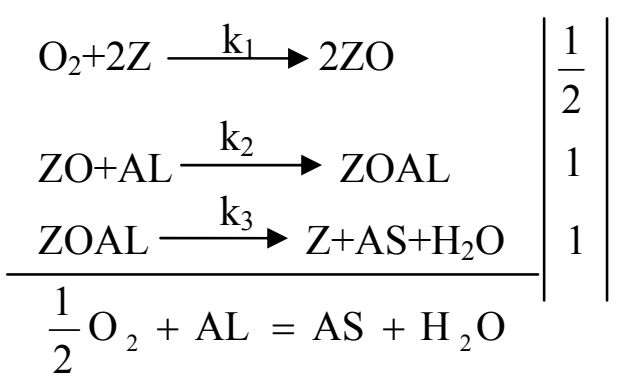

All of these stages are virtually irreversible. Assuming their elementarity, we can write the expressions for stage rates:

$$
\mathrm{r}_{1}=\mathrm{k}_{1} \mathrm{P}_{\mathrm{O}_{2}} \theta_{1}^{2} ; \mathrm{r}_{2}=\mathrm{k}_{2} \mathrm{P}_{\mathrm{AL}} \theta_{2} ; \mathrm{r}_{3}=\mathrm{k}_{3} \theta_{3}
$$

Here $\theta_{1}, \theta_{2}$ and $\theta_{3}$ - are fractions of the following regions of the modified zeolite, respectively: free regions that can adsorb oxygen, region covered with atomic oxygen, regions covered with atomic sorbed oxygen and molecules of isopropyl alcohol. $\mathrm{k}_{1}, \mathrm{k}_{2}$ and $\mathrm{k}_{3}$ are the rate constants; $\mathrm{r}_{1}, \mathrm{r}_{2}$ and $\mathrm{r}_{3}$ are the rates of the respective stages; $\mathrm{P}_{\mathrm{O}_{2}}, \mathrm{P}_{\mathrm{AL}}$ partial pressures corresponding to the component index.
Under stationary conditions:

$$
\mathrm{r}=\mathrm{r}_{1}=\mathrm{r}_{2}=\mathrm{r}_{3} \text {, }
$$

where $r$ is the overall rate of the process.

Based on these equations and constancy of the total number of surface regions $\left(\theta_{1}+\theta_{2}+\theta_{3}=1\right)$, the concentrations of intermediates $\theta_{\mathrm{i}}$, and the rate of formation for acetone $\left(\mathrm{r}_{\mathrm{AS}}\right)$ can be found as the function of reactants.

$$
\begin{aligned}
& \mathrm{k}_{1} \mathrm{P}_{\mathrm{O}_{2}} \theta_{1}^{2}=\mathrm{k}_{2} \mathrm{P}_{\mathrm{AL}} \theta_{2} ; \theta_{2}=\frac{\mathrm{k}_{1} \mathrm{P}_{\mathrm{O}_{2}}}{\mathrm{k}_{2} \mathrm{P}_{\mathrm{AL}}} \theta_{1}^{2} \\
& \mathrm{k}_{1} \mathrm{P}_{\mathrm{O}_{2}} \theta_{1}^{2}=\mathrm{k}_{3} \theta_{3} ; \quad \theta_{3}=\frac{\mathrm{k}_{1} \mathrm{P}_{\mathrm{O}_{2}}}{\mathrm{k}_{3}} \theta_{1}^{2}
\end{aligned}
$$

Substituting expressions $\theta_{2}, \theta_{3}$ into equation of the total number of surface regions, we obtain:

$$
\left(\frac{\mathrm{k}_{1} \mathrm{P}_{\mathrm{O}_{2}}}{\mathrm{k}_{2} \mathrm{P}_{\mathrm{AL}}}+\frac{\mathrm{k}_{1} \mathrm{P}_{\mathrm{O}_{2}}}{\mathrm{k}_{3}}\right) \theta_{1}^{2}+\theta_{1}-1=0
$$

Solving equation (4), we obtain the following expression for $\theta_{1}$ :

$$
\theta_{1}=\frac{\sqrt{1+4\left(\frac{\mathrm{k}_{1} \mathrm{P}_{\mathrm{O}_{2}}}{2 \mathrm{k}_{2} \mathrm{P}_{\mathrm{AL}}}+\frac{\mathrm{k}_{1} \mathrm{P}_{\mathrm{O}_{2}}}{2 \mathrm{k}_{3}}\right)}-1}{2\left(\frac{\mathrm{k}_{1} \mathrm{P}_{\mathrm{O}_{2}}}{2 \mathrm{k}_{2} \mathrm{P}_{\mathrm{AL}}}+\frac{\mathrm{k}_{1} \mathrm{P}_{\mathrm{O}_{2}}}{2 \mathrm{k}_{3}}\right)}
$$

Thus, equation of the rate of formation of acetone can be presented in the following form:

$$
\mathrm{r}_{\mathrm{AS}}=\mathrm{k}_{1} \mathrm{P}_{\mathrm{O}_{2}}\left\{\frac{\sqrt{1+4\left(\frac{\mathrm{k}_{1} \mathrm{P}_{\mathrm{O}_{2}}}{2 \mathrm{k}_{2} \mathrm{P}_{\mathrm{AL}}}+\frac{\mathrm{k}_{1} \mathrm{P}_{\mathrm{O}_{2}}}{2 \mathrm{k}_{3}}\right)}-1}{2\left(\frac{\mathrm{k}_{1} \mathrm{P}_{\mathrm{O}_{2}}}{2 \mathrm{k}_{2} \mathrm{P}_{\mathrm{AL}}}+\frac{\mathrm{k}_{1} \mathrm{P}_{\mathrm{O}_{2}}}{2 \mathrm{k}_{3}}\right)}\right\}^{2}
$$


Carbon dioxide is formed by interaction of weakly adsorbed isopropyl alcohol molecules with adsorbed oxygen molecules, according LangmuirHinshelwood mechanism. Kinetic equation corresponding to this mechanism has the form:

$$
\mathrm{r}_{\mathrm{CO}_{2}}=\frac{\mathrm{k}_{4} \mathrm{~K}_{1} \mathrm{~K}_{2} \mathrm{P}_{\mathrm{O}_{2}} \mathrm{P}_{\mathrm{AL}}}{\left(1+\mathrm{K}_{1} \mathrm{P}_{\mathrm{O}_{2}}+\mathrm{K}_{2} \mathrm{P}_{\mathrm{AL}}\right)^{2}}
$$

$\mathrm{K}_{1}, \mathrm{~K}_{2}-$ adsorption equilibrium constants of oxygen and isopropyl alcohol; $\mathrm{k}_{4}-$ constant of the rate of formation of carbon dioxide.

On the basis of kinetic scheme (1), we can write the following brutto-stoichiometric equations for the formation of acetone and carbon dioxide from isopropyl alcohol:

$$
\begin{aligned}
& i-\mathrm{C}_{3} \mathrm{H}_{7} \mathrm{OH}+\frac{1}{2} \mathrm{O}_{2} \rightarrow \mathrm{CH}_{3}-\mathrm{CO}-\mathrm{CH}_{3}+\mathrm{H}_{2} \mathrm{O} \\
& i-\mathrm{C}_{3} \mathrm{H}_{7} \mathrm{OH}+4.5 \mathrm{O}_{2} \rightarrow 3 \mathrm{CO}_{2}+\mathrm{H}_{2} \mathrm{O}
\end{aligned}
$$

Using these equations, yields of reaction products and initial molar amounts of isopropyl alcohol $\mathrm{n}_{\mathrm{AL}}^{0}$ and oxygen $\mathrm{n}_{\mathrm{O}_{2}}^{0}$, we determine the current molar rates of the reagents in the stream for AL, AS, $\mathrm{CO}_{2}, \mathrm{He}, \mathrm{O}_{2}, \mathrm{H}_{2} \mathrm{O}$, respectively, according to the following equations:

$$
\left\{\begin{array}{l}
\mathrm{n}_{\mathrm{AL}}=\mathrm{n}_{\mathrm{AL}}^{0}-\left(\mathrm{A}_{1} \mathrm{n}_{\mathrm{AL}}^{0}+\mathrm{A}_{2} \mathrm{n}_{\mathrm{AL}}^{0}\right) / 100=\mathrm{n}_{\mathrm{AL}}^{0}-\mathrm{n}_{\mathrm{AL}}^{0}\left(\mathrm{~A}_{1}+\mathrm{A}_{2}\right) / 100 \\
\mathrm{n}_{\mathrm{AS}}=\mathrm{A}_{1} \mathrm{n}_{\mathrm{AL}}^{0} / 100 \\
\mathrm{n}_{\mathrm{CO}_{2}}=3 \mathrm{~A}_{2} \mathrm{n}_{\mathrm{AL}}^{0} / 100 \\
\mathrm{n}_{\mathrm{He}}=\mathrm{n}_{\mathrm{He}}^{0} \\
\mathrm{n}_{\mathrm{O}_{2}}=\mathrm{n}_{\mathrm{O}_{2}}^{0}-\left(\frac{1}{2} \mathrm{~A}_{1} \mathrm{n}_{\mathrm{AL}}^{0}+4 \frac{1}{2} \mathrm{~A}_{2} \mathrm{n}_{\mathrm{AL}}^{0}\right) / 100 \\
\mathrm{n}_{\mathrm{H}_{2} \mathrm{O}}=\left(\mathrm{A}_{1} \mathrm{n}_{\mathrm{AL}}^{0}+\mathrm{A}_{2} \mathrm{n}_{\mathrm{AL}}^{0}\right) / 100
\end{array}\right.
$$

Here $A_{1}-A_{2}$ - yields of the reaction products (AS, $\mathrm{CO}_{2}$ ).

The feed rate of the total amount of reactants defines with relevant transformations like this:

$$
\sum \mathrm{n}_{\mathrm{i}}=\mathrm{n}_{\mathrm{AL}}+\mathrm{n}_{\mathrm{AS}}+\mathrm{n}_{\mathrm{CO}_{2}}+\mathrm{n}_{\mathrm{He}}^{0}+\mathrm{n}_{\mathrm{O}_{2}}+\mathrm{n}_{\mathrm{H}_{2} \mathrm{O}}
$$

The partial pressure of the reactants expressed by the equation:

$$
\mathrm{P}_{\mathrm{i}}=\frac{\mathrm{n}_{\mathrm{i}}}{\sum \mathrm{n}_{\mathrm{i}}} \mathrm{P},
$$

where $\mathrm{P}$ is a total pressure equal to 1 atm.

Equations (5), (6) and (7) form the kinetic model of the process.

Calculation of pre-exponential factors of the reaction constants $\operatorname{lnk} \mathrm{k}_{\mathrm{i}}^{0}, \operatorname{lnK}_{\mathrm{i}}^{0}$, activation energies
$E_{i}$ and heats of adsorption $Q_{i}$ were performed on Matlab software package by using simplex search method of Nelder-Mead ${ }^{10}$, where the objective function has the form:

$$
\mathrm{F}=\sum_{\mathrm{j}=1}^{\mathrm{m}} \sum_{\mathrm{i}=1}^{\mathrm{n}}\left(\frac{\left|\mathrm{A}_{\mathrm{ji}}^{\mathrm{EXP}}-\mathrm{A}_{\mathrm{ji}}^{\mathrm{CAL}}\right|}{\mathrm{A}_{\mathrm{ji}}^{\mathrm{CAL}}}\right) \rightarrow \min
$$

Here $\mathrm{A}_{\mathrm{ji}}^{\mathrm{EXP}}, \mathrm{A}_{\mathrm{ji}}^{\mathrm{CAL}}-$ the experimental and calculated values of the outputs of the i-th component in the $j$-th experiment; m-number of experiments; $\mathrm{n}$-number of components.

Numerical values of the constants of the kinetic model presented in the Table 2.

Table 2

The numerical values of the constants of the kinetic model

\begin{tabular}{c|l|l|l|l}
\hline № & \multicolumn{2}{|c|}{$\operatorname{lnk}^{0}, \operatorname{lnK}^{0}$} & \multicolumn{2}{|c}{$\mathrm{E}, \mathrm{Q}, \mathrm{kkal} / \mathrm{mole}$} \\
\hline 1 & $\operatorname{lnk}_{1}^{0}$ & 7.17 & $\mathrm{E}_{1}$ & 6.88 \\
2 & $\operatorname{lnk}_{2}^{0}$ & 3.88 & $\mathrm{E}_{2}$ & 5.85 \\
3 & $\operatorname{lnk}_{3}^{0}$ & 13.52 & $\mathrm{E}_{3}$ & 8.67 \\
\hline
\end{tabular}


Table 2 (continued)

\begin{tabular}{l|l|l|l|l}
\hline 4 & $\operatorname{lnk}_{4}^{0}$ & 19.82 & $\mathrm{E}_{4}$ & 25.61 \\
5 & $\operatorname{lnK}_{1}^{0}$ & 1.04 & $\mathrm{Q}_{1}$ & 2.87 \\
6 & $\operatorname{lnK}_{2}^{0}$ & 2.65 & $\mathrm{Q}_{2}$ & 3.93 \\
\hline
\end{tabular}

\section{CONCLUSION}

In the reaction of oxidative conversion of isopropyl alcohol to acetone over modified zeolite catalysts has been found that the natural mordenite containing $0.5 \%$ (wt.) $\mathrm{Cu}^{2+}$ and $0.1 \% \mathrm{Pd}^{2+}$ (wt.) shows the highest activity. On the basis of literature and experimental kinetic data has been suggested the simplified scheme of the stepwise mechanism of the reaction and developed theoretically grounded kinetic model for this process. The kinetic model of the reaction of gasphase catalytic oxidation of isopropyl alcohol to acetone adequately describes the experimental data. At numerical values of the kinetic model shown in the Table 2 the relative error of experimental and theoretically calculated data does not exceed $5.0 \%$. On this basis, we conclude: the proposed kinetic model in the studied range of variation of parameters describes quite well the mechanism of the reaction and can be used to develop the mathematical model of the process.

\section{REFERENCES}

1. I. N. Yukelson, "Technology of basic organic synthesis", Moscow: Chemistry, 1968, p. 846.

2. N. N. Lebedev, "Chemistry and Technology of basic organic and petrochemical synthesis", Moscow: Chemistry, 1981, p. 608.

3. P. E. Hathaway, M. E. Davis, J. Catal., 1989, 116, 263-278.

4. X. I. Areshidze, G. O. Chivadze, D. K. Ioseliani, Proceedings of the conference on geology, physical and chemical sciences and using of natural zeolites, Tbilisi, 1981, 258-260.

5. T. N. Shaxtaxtinski, A. M. Aliyev, S. M. Medjidova, USSR Patent 1817768, May 23, 1993.

6. S. S. Fatullaeva, Cand. Diss. of Chem. Sciences, Baku, 2004, p. 171.

7. A. M. Aliyev, S. M. Medjidova, A. A. Saridjanov, Azerb. Chem. J., 2011, 4, 9-16.

8. T. N. Shaxtaxtinski, A. M. Aliyev, A. R. Kuliyev, Doklady Earth Sciences., 1995, 343, 496-499.

9. T. N. Shaxtaxtinski, A. M. Aliyev, Kinetics Catalysis, 1996, 37, 286-290.

10. J. C. Lagarias, J. A. Reeds, M. H. Wright, P. E. Wright, SIAM J. Optimization, 1998, 9, 112-125. 
